Published in final edited form as:

Curr Psychiatry Rep. 2015 May ; 17(5): 28. doi:10.1007/s11920-015-0569-x.

\title{
Ophthalmology Issues in Schizophrenia
}

\section{Carolina P. B. Gracitelli,}

Hamilton Glaucoma Center and Department of Ophthalmology, University of California, 9500 Gilman Drive, La Jolla, CA 92093-0946, USA; Department of Ophthalmology, Federal University of São Paulo, Botucatu Street, 821. Vila Clementino, São Paulo, SP 04023-062, Brazil

\section{Ricardo Y. Abe,}

Hamilton Glaucoma Center and Department of Ophthalmology, University of California, 9500 Gilman Drive, La Jolla, CA 92093-0946, USA; rabe@ucsd.edu; Department of Ophthalmology, University of Campinas, Vital Brasil Street, 251, Cidade Universitária Zeferino Vaz, Campinas, SP 13083-970, Brazil

\section{Alberto Diniz-Filho, \\ Hamilton Glaucoma Center and Department of Ophthalmology, University of California, 9500 Gilman Drive, La Jolla, CA 92093-0946, USA; adinizfilho@gmail.com; Department of Ophthalmology and Otorhinolaryngology, Federal University of Minas Gerais, Alfredo Balena Avenue, 190 Santa Efigenia, Belo Horizonte, MG 30130-100, Brazil \\ Fabiana Benites Vaz-de-Lima, Department of Psychiatry, Federal University of São Paulo, São Paulo, Brazil; benites@uol.com.br}

Augusto Paranhos Jr., and Department of Ophthalmology, Federal University of São Paulo, Botucatu Street, 821. Vila Clementino, São Paulo, SP 04023-062, Brazil; paranhos@gmail.com

\section{Felipe A. Medeiros}

Hamilton Glaucoma Center and Department of Ophthalmology, University of California, 9500 Gilman Drive, La Jolla, CA 92093-0946, USA; fmedeiros@ucsd.edu

\author{
Abstract \\ Schizophrenia is a complex mental disorder associated with not only cognitive dysfunctions, such \\ as memory and attention deficits, but also changes in basic sensory processing. Although most \\ studies on schizophrenia have focused on disturbances in higher-order brain functions associated \\ C. P. B. Gracitelli carolepm@gmail.com. \\ Compliance with Ethics Guidelines \\ Conflict of Interest Carolina P. B. Gracitelli, Ricardo Y. Abe, and Alberto Diniz-Filho declare that they have no conflict of interest. \\ Fabiana Benites Vaz-de-Lima is a medical manager for Abbvie. Augusto Paranhos Jr. is a consultant for Allergan, Inc. Felipe A. \\ Medeiros has received financial support from Alcon Laboratories Inc., Bausch \& Lomb, Carl Zeiss Meditec Inc., Heidelberg \\ Engineering, Inc., Merck Inc., Allergan Inc., Sensimed, Topcon, Inc, Reichert, Inc., National Eye Institute. Research grant-Alcon \\ Laboratories Inc., Allergan Inc., Carl Zeiss Meditec Inc., Reichert Inc. Consultant-Allergan, Inc., Carl-Zeiss Meditec, Inc.; Novartis. \\ Human and Animal Rights and Informed Consent This article does not contain any studies with human or animal subjects \\ performed by any of the authors. \\ This article is part of the Topical Collection on Schizophrenia and Other Psychotic Disorders
}


with the prefrontal cortex or frontal cortex, recent investigations have also reported abnormalities in low-level sensory processes, such as the visual system. At very early stages of the disease, schizophrenia patients frequently describe in detail symptoms of a disturbance in various aspects of visual perception that may lead to worse clinical symptoms and decrease in quality of life. Therefore, the aim of this review is to describe the various studies that have explored the visual issues in schizophrenia.

\section{Keywords}

Schizophrenia; Visual impairment; Visual deficits; Dopamine; Glutamate

\section{Introduction}

Schizophrenia is a chronic and relapsing disorder characterized by a mixture of cognitive, positive, negative, and mood symptoms [1]. Because of the debilitating and lifelong clinical course, the disease is a major cause of disability in the world [1]. Genetic and environmental factors are involved in the pathophysiology of schizophrenia, which is considered a multifactorial neurodevelopmental disorder [2-4]. Recent data from several independent studies have shown replicable associations of single nucleotide polymorphisms in genes of the major histocompatibility complex [2-4]. These studies have also indicated that early brain development is affected in the disease [2-4].

There is clear evidence of early visual processing deficits in schizophrenia patients $[5,6]$. Such deficits may include reduced sensitivity to contrast [7,8], deficits in motion processing [9] and spatial-temporal integration, as well as reduced visual event-related potential amplitudes [10] and neurophysiologic response to visual stimuli [6]. However, although visual impairment can affect activities of daily living and might subtend their clinical symptoms [11••], there is not a clear understanding of how the visual perception deficits are associated with clinical symptoms in the disease and impact on quality of life.

In this review, we critically evaluate the existing literature on this topic. We also discuss issues related to how ophthalmological symptoms may affect these patients and how their monitoring can help the management of this disorder.

\section{Dopamine and Glutamine Role}

Although some authors have proposed that schizophrenia is a neurodevelopmental disorder associated with alterations in brain circuits, the understanding of these changes in normal and abnormal cortical development remains unclear [4]. Alterations in the dopamine and glutamate systems have been implicated in the pathophysiology of the disease, and recent work has focused on the combined interactions of these two systems [12].

According to the dopamine hypothesis, the dopamine systems in the mesolimbic pathway may contribute to the "positive symptoms" of schizophrenia, whereas those in the mesocortical pathway may be responsible for the "negative symptoms" [13]. The main sources of evidence supporting these claims are that amphetamine, cocaine, and similar 
drugs that increase levels of dopamine in the brain may cause symptoms that resemble those present in psychosis. In addition, a group of drugs called phenothiazines, which includes antipsychotics such as chlorpromazine, has been found to antagonize dopamine binding (particularly at the D2 dopamine receptors) and reduce positive psychotic symptoms [13].

The role played by dopamine in the visual system may assist in understanding the effects of schizophrenia on the visual system [13,14]. Dopamine is a major neurotransmitter and modulator in the retina [14] and plays a major function in the signaling of retinal amacrine and interplexiform cells. As light enters the eye, it is first detected by photoreceptors (cones and rods). The photoreceptors synapse directly onto bipolar cells, which in turn synapse onto ganglion cells of the outermost layer, which will then conduct action potentials to the brain. In addition, other neurons in the retina, particularly horizontal and amacrine cells, transmit information laterally (from a neuron in one layer to an adjacent neuron in the same layer), resulting in more complex receptive fields that can be either indifferent to color and sensitive to motion or sensitive to color and indifferent to motion. Thus, the amacrine cells have a fundamental role in integrating the signals between bipolar and retinal ganglion cells [15]. The main effect of dopamine on amacrine cells is the uncoupling of electronic junctions that link some of them. As one of the basic classes of retinal neurons [16], they play an essential role in dark adaption of the retina. They appear to be a feedback pathway [17], carrying information from the inner plexiform layer, back to the outer plexiform layer. In an animal study, Bodis-Wollner et al. [18] revealed that a retina with dopaminergic deficiency loses a subset of retinal amacrine cells [18]. Additionally, as dopamine is involved in the physiological (e.g., darkness adaptation) activities of retinal ganglion cells, the dopamine dysfunction that occurs in schizophrenia may alter visual processing by modifying the receptive field properties of ganglion cells [14].

Neural excitotoxicity due to excess of glutamate has also been suggested to be related to the process of neurodegeneration in schizophrenia [19]. The glutamatergic system is the major excitatory system of the human central nervous system and is involved in basic functions such as cognitive learning and memory [20]. Glutamate imbalances appear to cause abnormal functioning in the dopamine system, and if the levels of glutamate are low, dopamine is overactive, resulting in the expression of schizophrenic symptoms [12]. Histologic analyses have found multiple glutamate receptors in the retina [21-25]. In addition, glutamate has also been described to exert a toxic effect by causing destruction of retinal ganglion cells [23].

\section{Structural Damage in Retinal Layers in Schizophrenia}

Although it is not clear if excessive glutamate can cause any structural damage to the optic nerve and retinal layers, leading to visual processing deficits in schizophrenia patients [26••], the loss of retinal nerve fiber layer (RNFL) thickness had been well established in several neurologic diseases which also involve dopamine dysregulation, such as Alzheimer's and Parkinson's disease. Therefore, pathologic activation of glutamate receptors might be related to neuronal damage [25, 27-29].

Based on the hypothesis that dopamine deregulation could cause structural defects in retinal layers in schizophrenia patients, Lee et al. [26••] evaluated a group of 30 schizophrenia 
patients and 30 age-matched controls with spectral-domain optical coherence tomography (SD-OCT). SD-OCT is a non-invasive and fast imaging technique able to assess the thickness of the RNFL and of the macular region. They found that these measurements were reduced in schizophrenia patients, suggesting that SD-OCT could be a useful tool for schizophrenia diagnosis and monitoring [26••]. These results agree with the study by Cabezon et al. [30] who showed significant average and superior peripapillary RNFL thinning in 30 schizophrenia patients. Ascaso et al. [31] found a significant difference between RNFL thickness in schizophrenia patients compared to healthy subjects in the nasal quadrant. Chu et al. [32] showed that there was no difference in the global RNFL thickness and macular volume in 38 schizophrenia patients compared to healthy controls; however, RNFL in the right nasal quadrant of the schizoaffective group was thinner than in the schizophrenia group ( $p=0.02$ ). These contradictory results are most likely due to small sample sizes and the use of different technologies to measure the RNFL thickness.

\section{Neuronal Visual Pathways}

The subcortical projections of the retina to the cerebral cortex are formed mainly by three pathways: magnocellular, parvocellular, and koniocellular. The characteristics of the two main pathways, magnocellular and parvocellular pathways are described in Table 1. The two systems have the origin in different types of retinal ganglion cells, occupy different layers in the lateral geniculate nucleus, and end in different input layers in the primary visual cortex [33••] where intermixing of the inputs occurs [33••]. From primary visual cortex, two cortical pathways have been described: the dorsal and ventral streams. Nowadays, different studies have demonstrated that Area V4 of the ventral stream receives significant substantial magnocellular input [34], and the middle temporal area of the dorsal stream receives significant parvocellular [35] and koniocellular input [36].

These pathways, which dominate primate vision [37], have distinct and complementary spatial, temporal, luminance, and chromatic stimulus preferences [38], as well as different dynamic responses $[39,40]$. The magnocellular pathway is formed by large neurons that conduct the visual stimulus to the dorsal visual fasciculus [41] and is responsible for transferring low spatial frequency and high temporal frequency information, which is associated with vision under low light conditions and noticing moving objects. The magnocellular pathway is also related to movement, stereopsis, spatial localization, depth perception, hyperacuity, figural grouping, illusory border perception, and figure/ground separation [42••]. The parvocellular pathway is formed by smaller neurons that project to the ventral visual fasciculus [41] and is responsible for transferring high spatial frequency and low temporal frequency information, which is correlated with detailed vision and seeing static objects. The koniocellular pathway is responsible to carry blue-yellow color signals [43]. Indeed, the diffuse connections of koniocellular pathway to superficial layers of the cerebral cortices have been invoked to propose that koniocellular activity gates cortical circuits fed by the magnocellular and parvocellular pathways. 


\section{Magnocellular Pathway and Schizophrenia}

Several studies have reported that visual impairment in schizophrenia patients could result from dysfunction in the magnocellular pathway and various techniques have been used to demonstrate this hypothesis [44, 45].

Deficits in magnocellular function in schizophrenia have been reported using steady-state visual-evoked potentials (ssVEP) [6,46], which is a type of VEP (i.e., brain response) to any visual stimuli. The magnocellular system is selectively activated by low luminance contrast stimuli $(<16 \%)$, and the parvocellular is selectively activated by high contrast level $(>16 \%)$ [10, 46]. Kim el al. [46] studied 13 schizophrenia patients and 11 healthy subjects by using ssVEP and concluded that deficits in motion processing in schizophrenia are significantly associated with reduced activity of the magnocellular vision systems [46]. However, recently, Skottun et al. [33••] suggested two main problems for these results using ssVEP. (1) In certain circumstances, the parvocellular system may respond to lower contrast stimuli than the magnocellular system. Because of this, relying on low-contrast stimuli to obtain a selective magnocellular response in psychophysical tests is likely to be unreliable and (2) there are other neurons that have similar functions to those of these 2 types of cells [33••].

Martinez et al. [44] used functional magnetic resonance imaging to investigate the potential role of magnocellular stream dysfunction in schizophrenia patients. They included 13 male schizophrenia patients and 11 healthy male volunteers who performed the imaging test. They found that schizophrenia patients presented reduced activity to low spatial frequencies in multiple areas of the parietal and temporal lobes [44]. Alternatively, studies using electroencephalography have shown reduced signal amplitudes in the posterior cortical regions along the magnocellular pathway in schizophrenia patients, with relatively normal activation along the pathway [6, 47].

Additionally, measurements of contrast sensitivity in psychosomatic tests were also another possibility that has been used to investigate the magnocellular pathway. Studies in monkeys performed by Merigan et al. [48-51] found that a reduction in contrast sensitivity following injury in magnocellular layers is limited to cases in which stimuli are characterized by low spatial frequency or high temporal frequency [48-51]. Psychosomatic research in humans has shown similar results $[52,53]$. However, although contrast sensitivity is the best established non-invasive test of magnocellular integrity, a review performed by Skottun et al. [45] found little evidence for magnocellular deficits. They concluded that there is a general trend for schizophrenia to show uniform reductions in contrast sensitivity; however, this could be related to problems with attention or the effects of medications [45].

Several studies have reported significant differences between patients with schizophrenia and control groups regarding the magnocellular pathway assessed by frequency doubling technology (FDT) [8, 54-57]. FDT has been proposed as a selective perimetric test that attempts to target the magnocellular cells. Vaz-de-Lima et al. [58•] using FDT found that schizophrenia patients had lower global mean sensitivity than healthy group $(p<0.009)$ [58•]. The same study analyzed the difference between the right and left hemispheres; however, they did not find differences between the right and left hemispheres [58•]. Although, there is evidence in the literature suggesting that schizophrenia patients had hypoactivation in the 
magnocellular pathway, particularly in the right hemisphere which is correlated with global information processing [59].

However, although the results of these previous studies are consistent with the magnocellular system malfunction in schizophrenia, other studies are in disagreement with this theory [45, 60-63]. There are substantial controversies over previous research methods, which highlight the need for a device capable of properly evaluating the magnocellular pathway and its functions. One reason for this lack of agreement is that all these tasks consider a specific deficit in schizophrenia (e.g., backward masking, motion processing, contrast sensitivity) or measure low spatial frequencies or high temporal frequencies, which are features of the magnocellular pathway.

\section{Parvocellular Pathway and Schizophrenia}

Various studies assert that visual deficits in schizophrenia patients are related to the parvocellular pathway or are related to the interaction between the magnocellular and parvocellular pathways $[61,64]$. Table 2 shows some of comparative studies of magnocellular and parvocellular pathway in schizophrenia. Because most of the experiments are based on visual stimuli containing spatial and temporal information processed by both magnocellular and parvocellular pathways $[8,69]$, it is difficult to discriminate which pathway or channel is involved in the early visual processing disorder.

Additionally, the predominant positive and negative symptoms that affect the patients may interfere with these results. There is evidence of differences in visual processing between the subgroups of patients with schizophrenia with predominantly positive and negative symptoms [64, 65]. Visual backward masking (VBM) has been used to test this assumption. The test refers to a phenomenon wherein presenting one visual image immediately after another target ( $\$ 50 \mathrm{~ms}$ ) leads to a failure to consciously perceive the first one [70]. In studies with VBM and contrast sensitivity, visual processing in the subgroup with predominantly positive symptoms was less involved as compared to the group with negative symptoms $[64,65]$. It is important to emphasize that the effect of antipsychotic drugs can also influence visual processing. In fact, patients without antipsychotic treatment had worse performance of VBM compared to the group who used antipsychotics. [71] Schechter et al., in another study [67], examined medicated patients using the VBM task. They showed that schizophrenia patients needed significantly longer inter-stimulus intervals than age-matched controls to escape from masking in the parvocellular target/magnocellular mask condition. Additionally, the critical stimulus durations for unmasked stimuli were significantly increased for both magnocellular and parvocellular targets in patients with schizophrenia. These results reported a significant impairment in the magnocellular but not parvocellular pathway in schizophrenia patients.

\section{Visual Deficits in Schizophrenia}

\section{Subjective Sensory Distortions}

A study performed by Phillipson et al. [72] with schizophrenia patients admitted to a general hospital showed that the incidence of visual distortion was $62 \%$. Distortions of brightness contrast were the most common, followed by motion distortion. Approximately $65 \%$ 
patients reported that these distortions were eliminated or significantly reduced with the treatment. Additionally, $54 \%$ of the patients reported that the drugs reduced the color, motion, and brightness distortion, whereas the other distortions were not affected [72]. Patients who reported visual distortions also tended to have visual hallucinations; however, $73 \%$ responded positively with the medications (i.e., chlorpromazine, haloperidol, and other antipsychotic dopamine blockers) [72].

\section{Contrast Sensitivity}

Harris et al. [73] found a decrease in contrast sensitivity in medium and high spatial frequencies ( 2 and 8 cycles/degree) and an increase in lower spatial frequencies ( 0.5 cycles/ degree) during neuroleptic administration in schizophrenia patients. Contrast thresholds were measured immediately before and 2-3 days after a regular, therapeutic injection of depot neuroleptic. Subjects were stabilized on depot injections of the neuroleptic with a mean inter-injection interval of 3 weeks. The drugs enhanced sensitivity at the low spatial frequency and reduced it at the medium and high spatial frequency. Additionally, after injection, subjects required more contrast to match the contrast of the high spatial frequency and less contrast to match that of the low spatial frequency, compared to the contrast of the medium spatial frequency. Pupillary measurements suggested that these effects were not due to drug-induced changes in pupil size. The changes in threshold produced by the presumed dopaminergic blockage were similar to those reported by Bodis-Wollner [74] in his comparison of patients with Parkinson and normal control subjects, with loss in sensitivity for medium and high spatial frequencies and an enhancement at low spatial frequencies. These results are consistent with the hypothesis that dopamine can participate in the organization of receptive field properties in the retina, influencing human vision. Another possible explanation is that dopamine blockage may increase the size of the excitatory centers of receptive fields, enlarging the contrast gain. Both effects have been suggested as physiological bases for dark adaptation, which are consistent with the luminance adaptation hypothesis of dopaminergic retinal function [75].

\section{Tilt After Effects}

The tilt after effects (TAE) is the observation of a temporary change in the perceived orientation of lines after having adapted to lines tilted in another direction. Specifically, if you stare at white and black bars tilted to the left for a while, then look at vertical bars, these will now appear to tilt slightly to the right. This phenomenon most likely occurs because the orientation-specific cells in the visual system become fatigued and are therefore temporarily less responsive. Calvert et al. [76] investigated the TAEs in chronic schizophrenia patients using neuroleptic drugs compared with Parkinson patients. They showed that if presenting peripheral fine gratings ( 10 cycles/degree), schizophrenia patients produced results similar to those with Parkinson, after their depot injection (i.e., if blood levels of the neuroleptic were presumably highest), simulating the effects of a decrease in stimulus contrast. In contrast, before their injection (i.e., if levels of the drug were presumably lower), TAEs of schizophrenics simulated the effects of an increase in stimulus contrast. These results suggested that dopamine receptor antagonist drugs may affect TAE via retinal mechanisms if using fine gratings because the retina contains the highest concentration of dopamine in the primary visual system and is the major site of contrast regulation [75]. 


\section{Color Discrimination}

Various studies have reported that schizophrenia patients make more color discrimination errors than control subjects, but no pattern emerged regarding a color-specific axis of deficit [77]. This finding is in contrast with other neuropsychiatric conditions that involve dopaminergic depletion, such as Parkinson disease, which is associated with color discrimination deficits along the blue color (tritan-wave-length-sensitive) axis [78]. Doses of antipsychotic medication were not correlated with better or worse performance on color discrimination. In recently diagnosed patients, who were not taking medication, the results for color discrimination did not differ from the normal subjects [79].

\section{Abnormalities in Eye Movements in Schizophrenia}

Smooth Pursuit Eye Movements-Smooth pursuit eye movements and saccades are two different types of oculomotor control. Smooth pursuit eye movements (SPEM) is elicited to track moving targets, and saccades are primarily directed toward stationary targets whereas [80]. Recently, behavioral and neurophysiological studies have demonstrated that both types of eye movements work in synergy for visual tracking.

The smooth pursuit system generates eye movements that track slowly moving targets. The function of the pursuit system is to maintain the image of the target on the fovea, and its primary input is most likely the velocity of the image on the retina [81-84]. The function of this system can be impaired by different reasons, including inattention, drugs that depress the central nervous system, loss of central vision, mental fatigue, or lesions of the ocular motor pathways in the cerebral hemispheres, brainstem, and cerebellum [85].

Abnormal SPEM in patients with schizophrenia was rediscovered by Diefendorf and Dodge [86] in 1908, suggesting that abnormal tracking may serve as a biological marker for schizophrenia. Studies in schizophrenia patients have found reduced pursuit gain, low initial acceleration, and abnormal gain-corrective saccade interactions [85, 87, 88]. For example, Yee et al. [85] studied the horizontal eye movements and compared 21 patients with schizophrenia, 13 patients with other psychiatric disorders, and 19 normal subjects. Eye velocity and closed-loop gain of pursuit, optokinetic nystagmus, vestibulo-ocular response, and visual-vestibular interactions were calculated. They concluded that the frequency and severity of eye movement abnormalities in schizophrenia patients were lower than those indicated by previous studies that used various techniques of analysis.

Different studies have suggested that SPEM is generated by two types of motion information. The motion of an attended object's image on the retina is a powerful visual sensory signal stimulating SPEM. The retinal control of SPEM is related to a posterior oculomotor pathway (including the middle temporal cortex and cerebellum) [89]. When the eyes achieve a velocity approximate to the object of interest, there is limited retinal motion. To keep accurate pursuit, the system is thought to use internal representations of the motor command and previous retinal motion information to predict target movement. Based on this hypothesis, Hong et al. [90] found that patients with schizophrenia had reduced pursuitrelated activation in several known extraretinal motion processing areas, including the frontal and supplemental eye fields, medial superior temporal cortex, and anterior cingulate 
[90] showing evidence of the reduced function in the extraretinal motion processing pathway in schizophrenia. These patients also presented increased activation in the medial occipitotemporal cortex suggesting an increased dependence on immediate retinal motion information, which may be used to compensate for reduced extraretinal signaling during sustained visual tracking [90].

Saccadic Movements-Saccadic eye movements have not been so extensively studied as SPEM in schizophrenia. Research has demonstrated that cerebral control of saccadic eye movements depends on several cortical and subcortical regions, more specifically in posterior parietal cortex [91]. Especially the voluntary saccades (e.g., antisaccades and remembered saccades) involve complex cortico-subcortical processes. In an antisaccade task, the patient has to move their eyes in the mirror position of a visual target. An antisaccade is created by inhibition of a reflexive saccade and by production of a voluntary saccade. In schizophrenia, the most frequent saccadic abnormality is found in antisaccades [92]. Likewise, deficits in remembered saccades (delayed latency) are reported in schizophrenia patients [93]. In addition, different studies have shown that voluntary saccades are impaired in patients with schizophrenia, whereas reflexive saccades are relatively well preserved [94•, 95•]. For example, one study performed by Bender et al. [94•] using functional MRI to look at brain activity during saccades found that patients with schizophrenia showed increased activity in several areas, particularly the supplementary eye fields and the prefrontal cortex, when performing volitional saccades. This finding was surprising, as frontal activation is usually reduced in schizophrenia. The author suggests that one hypothesis for this finding is that increased neural activity in these areas is required to generate volitional saccades, possibly because neurons in these areas act inefficiently in schizophrenia.

In addition, saccadic adaptation is impaired in patients with schizophrenia who have subtle neurological impairment ("neurological soft signs") [95•]. Patients were slower than agematched controls to adapt to stepped stimuli in which saccadic dysmetria was artificially produced by moving the target during saccades. This sort of abnormality is usually seen in cerebellar dysfunction, something that was unexpected in schizophrenia.

Vergence Eye Movements-As described before, previous studies have shown that smooth pursuit eye movements and antisaccades are impaired in patients with schizophrenia $[85,87,88]$. However, under normal viewing conditions, targets move not only in the frontoparallel plane but also in depth, and tracking them requires both smooth pursuit and vergence eye movements [96]. Although previous studies in humans and non-human primates suggest that these two eye movement subsystems are relatively independent of one another [85, 87, 88], few studies have addressed vergence movement behavior in schizophrenia patients [96]. The study performed by Bolding et al. found that patients with schizophrenia exhibited substantially lower gains compared to healthy controls during vergence tracking at all tested speeds (e.g., $0.25 \mathrm{~Hz}$ vergence tracking mean gain of 0.59 vs. 0.86). In addition, patients with schizophrenia exhibited significantly lower gains than healthy controls during smooth pursuit at higher target speeds (e.g., $0.5 \mathrm{~Hz}$ smooth pursuit mean gain of 0.64 vs. 0.73$)$. And there was a modest $\left(R^{2}=0.5\right)$, but significant, correlation 
between smooth pursuit and vergence tracking performance in patients with schizophrenia. These findings suggest substantial vergence tracking deficits in patients with schizophrenia [96]. Table 3 summarizes some characteristics of visual deficits in schizophrenia.

\section{Visual Perception and Endophenotypes}

The potential significance of visual dysfunctions as endophenotypes of schizophrenia has been discussed [6, 47, 66]. Gottesman et al. [100] defined the endophenotypes of an illness as having the following characteristics: are associated with the illness, are present in unaffected biological relatives at a higher rate than in the general population, are heritable, and are detectable in remitted patients. Deficits in working memory, executive function, sustained attention, sensory gating, smooth pursuit eye movements, verbal memory, and language production all have been identified as endophenotypes of schizophrenia [100].

Various studies have tried to investigate visual perception as a new endophenotype [101, 102]. Green et al. [103] showed impaired VBM performance in unaffected siblings of schizophrenia patients, and a few years later, the same author [104] replicated these findings in an independent sample of siblings of schizophrenia patients, but the same results were not observed in siblings of patients with different mental diseases such as bipolar disease [102]. Relatives of schizophrenia patients showed more pronounced deficits if the interval between target and mask was short and if the target location was perceived [101, 102]. Chen et al. [101] found compromised motion perception in relatives of schizophrenia patients, which was related to smooth pursuit eye movement deficits.

Keri et al. [66] investigated whether magnocellular pathway impairment was an endophenotype of schizophrenia by using vernier threshold measurements in 72 patients with schizophrenia and their 86 unaffected siblings. General intellectual function, executive function, oculomotor scanning, psychomotor speed, and verbal memory were also assessed to investigate the relationship between visual-perceptual and higher level cognitive impairments. They found that siblings of schizophrenia patients displayed significant impairments during the vernier tasks that are biased toward the magnocellular pathway, whereas their performance was adequate in the parvocellular pathway conditions. A few years later, Gracitelli et al. [68••] evaluated the magnocellular visual pathway deficit in schizophrenia patients and compared it with their parents. A total of 13 patients, 13 parents, and 12 healthy controls were enrolled and performed the FDT test. They found that the mean deviation in FDT was higher in control subjects compared with schizophrenia patients $(p=0.020)$ and their parents $(p=0.037)$. These findings suggest that a visual process deficit may be an endophenotype of schizophrenia [68••], and the evaluation of this area could be used to distinguish people who have a higher risk for schizophrenia.

\section{Conclusion}

Schizophrenia is associated with consistent deficits in visual processing in the early stage of the disease. The deficits can be noticed in various tasks, including contrast detection, motion perception, and eye movement control. The neurophysiology of these processes involves deregulation of glutamatergic activity to dopamine receptors and interactions between 
magnocellular and parvocellular pathways. It is true that ophthalmological assessment may contribute to the diagnosis of early-stage visual processing deficits in patients with schizophrenia and their relatives. However, future investigations should help clarify how the visual perception deficits are associated with clinical symptoms of schizophrenia and how it can impact on quality of life.

\section{References}

Papers of particular interest, published recently, have been highlighted as:

- Of importance

•• Of major importance

1. Report WHOMH. Mental Health: New understanding. Geneva World Health Organization; New Hope: 2001.

2. Stefansson H, Ophoff RA, Steinberg S, et al. Common variants conferring risk of schizophrenia. Nature. 2009; 460:744-7. [PubMed: 19571808]

3. International Schizophrenia C. Purcell SM, Wray NR, et al. Common polygenic variation contributes to risk of schizophrenia and bipolar disorder. Nature. 2009; 460:748-52. [PubMed: 19571811]

4. Insel TR. Rethinking schizophrenia. Nature. 2010; 468:187-93. [PubMed: 21068826]

5. Yeap S, Kelly SP, Sehatpour P, et al. Visual sensory processing deficits in Schizophrenia and their relationship to disease state. Eur Arch Psychiatry Clin Neurosci. 2008; 258:305-16. [PubMed: 18504634]

6. Butler PD, Schechter I, Zemon V, et al. Dysfunction of early-stage visual processing in schizophrenia. Am J Psychiatry. 2001; 158:1126-33. [PubMed: 11431235]

7. Butler PD, Javitt DC. Early-stage visual processing deficits in schizophrenia. Curr Opin Psychiatry. 2005; 18:151-7. [PubMed: 16639168]

8. Slaghuis WL. Contrast sensitivity for stationary and drifting spatial frequency gratings in positiveand negative-symptom schizophrenia. J Abnorm Psychol. 1998; 107:49-62. [PubMed: 9505038]

9. Chen Y, Levy DL, Sheremata S, et al. Compromised late-stage motion processing in schizophrenia. Biol Psychiatry. 2004; 55:834-41. [PubMed: 15050865]

10. Butler PD, Zemon V, Schechter I, et al. Early-stage visual processing and cortical amplification deficits in schizophrenia. Arch Gen Psychiatry. 2005; 62:495-504. [PubMed: 15867102]

11 ••. Giersch A, Lalanne L, van Assche M, et al. On disturbed time continuity in schizophrenia: an elementary impairment in visual perception? Front Psychol. 2013; 4:281. [PubMed: 23755027] This manuscript review the mechanisms involved in the sense of time continuity and clinical evidence that they are impaired in schizophrenia.

12. Javitt DC. Glutamate and schizophrenia: phencyclidine N-methyl-D-aspartate receptors, and dopamine-glutamate interactions. Int Rev Neurobiol. 2007; 78:69-108. [PubMed: 17349858]

13. Carlsson A. The current status of the dopamine hypothesis of schizophrenia. Neuropsychopharmacol: Off Publ Am Coll Neuropsychopharmacol. 1988; 1:179-86.

14. Djamgoz MB, Hankins MW, Hirano J, et al. Neurobiology of retinal dopamine in relation to degenerative states of the tissue. Vis Res. 1997; 37:3509-29. [PubMed: 9425527]

15. Frederick JM, Rayborn ME, Laties AM, et al. Dopaminergic neurons in the human retina. J Comp Neurol. 1982; 210:65-79. [PubMed: 6127354]

16. Haft M, van Hemmen JL. Theory and implementation of infomax filters for the retina. Network. 1998; 9:39-71. [PubMed: 9861978]

17. Behrens U, Wagner HJ. Terminal nerve and vision. Microsc Res Tech. 2004; 65:25-32. [PubMed: 15570588]

18. Bodis-Wollner I. Visual deficits related to dopamine deficiency in experimental animals and Parkinson's disease patients. Trends Neurosci. 1990; 13:296-302. [PubMed: 1695407] 
19. Deutsch SI, Rosse RB, Schwartz BL, et al. A revised excitotoxic hypothesis of schizophrenia: therapeutic implications. Clin Neuropharmacol. 2001; 24:43-9. [PubMed: 11290881]

20. Bressan RA, Pilowsky LS. Glutamatergic hypothesis of schizophrenia. Rev Bras Psiquiatr (Sao Paulo, Brazil: 1999). 2003; 25:177-83.

21. Jojich L, Pourcho RG. Glutamate immunoreactivity in the cat retina: a quantitative study. Vis Neurosci. 1996; 13:117-33. [PubMed: 8730994]

22. Ehinger B, Ottersen OP, Storm-Mathisen J, et al. Bipolar cells in the turtle retina are strongly immunoreactive for glutamate. Proc Natl Acad Sci U S A. 1988; 85:8321-5. [PubMed: 2903503]

23. Sucher NJ, Lipton SA, Dreyer EB. Molecular basis of glutamate toxicity in retinal ganglion cells. Vis Res. 1997; 37:3483-93. [PubMed: 9425525]

24. Peng YW, Blackstone CD, Huganir RL, et al. Distribution of glutamate receptor subtypes in the vertebrate retina. Neuroscience. 1995; 66:483-97. [PubMed: 7477889]

25. Lipton SA, Rosenberg PA. Excitatory amino acids as a final common pathway for neurologic disorders. N Engl J Med. 1994; 330:613-22. [PubMed: 7905600]

$26 \bullet$. Lee WW, Tajunisah I, Sharmilla K, et al. Retinal nerve fiber layer structure abnormalities in schizophrenia and its relationship to disease state: evidence from optical coherence tomography. Invest Ophthalmol Vis Sci. 2013; 54:7785-92. [PubMed: 24135757] The first study evaluating the RNFL thickness in schizophrenic patients using spectral domain OCT (SD-OCT) and also evaluated schizophrenic patients in different phases of the disease.

27. Parisi V, Restuccia R, Fattapposta F, et al. Morphological and functional retinal impairment in Alzheimer's disease patients. Clin Neurophysiol: Off J Int Fed Clin Neurophysiol. 2001; 112:1860-7.

28. Lu Y, Li Z, Zhang X, et al. Retinal nerve fiber layer structure abnormalities in early Alzheimer's disease: evidence in optical coherence tomography. Neurosci Lett. 2010; 480:69-72. [PubMed: 20609426]

29. Inzelberg R, Ramirez JA, Nisipeanu P, et al. Retinal nerve fiber layer thinning in Parkinson disease. Vis Res. 2004; 44:2793-7. [PubMed: 15342223]

30. Cabezon L, Ascaso F, Ramiro P, et al. Optical coherence tomography: a window into the brain of schizophrenic patients. Acta ophthalmology. 2012; 90

31. Ascaso F, Cabezon L, Quintanilla MA, et al. Retinal nerve fiber layer thickness measured by optical coherence tomography in patients with schizophrenia: a short report. Eur J Psychiatry. 2010; 24:227-35.

32. Chu EM, Kolappan M, Barnes TR, et al. Awindow into the brain: an in vivo study of the retina in schizophrenia using optical coherence tomography. Psychiatry Res. 2012; 203:89-94. [PubMed: 22917503]

$33 \bullet$. Skottun BC, Skoyles JR. On identifying magnocellular and parvocellular responses on the basis of contrast-response functions. Schizophr Bull. 2011; 37:23-6. [PubMed: 20929967] The study discuss the issue of assess the magnocellular and parvocellular sensitivity in schizophrenic individuals using steady-state visually evoked potentials (VEPs).

34. Ferrera VP, Nealey TA, Maunsell JH. Responses in macaque visual area V4 following inactivation of the parvocellular and magnocellular LGN pathways. J Neurosci: Off J Soc Neurosci. 1994; 14:2080-8.

35. Nassi JJ, Lyon DC, Callaway EM. The parvocellular LGN provides a robust disynaptic input to the visual motion area MT. Neuron. 2006; 50:319-27. [PubMed: 16630841]

36. Sincich LC, Park KF, Wohlgemuth MJ, et al. Bypassing V1: a direct geniculate input to area MT. Nat Neurosci. 2004; 7:1123-8. [PubMed: 15378066]

37. Nassi JJ, Callaway EM. Parallel processing strategies of the primate visual system. Nature reviews. Neuroscience. 2009; 10:360-72. [PubMed: 19352403]

38. Shapley R. Visual sensitivity and parallel retinocortical channels. Annu Rev Psychol. 1990; 41:635-58. [PubMed: 2407178]

39. Maunsell JH, Ghose GM, Assad JA, et al. Visual response latencies of magnocellular and parvocellular LGN neurons in macaque monkeys. Vis Neurosci. 1999; 16:1-14. [PubMed: $10022474]$ 
40. Schiller PH, Malpeli JG. Functional specificity of lateral geniculate nucleus laminae of the rhesus monkey. J Neurophysiol. 1978; 41:788-97. [PubMed: 96227]

41. Shapley R, Reid RC, Kaplan E. Receptive fields of P and M cells in the monkey retina and their photoreceptor inputs. Neuroscience research. Suppl: Off J Japan Neurosci Soc. 1991; 15:S199_ 211.

$42 \bullet$. Denison RN, Vu AT, Yacoub E, et al. Functional mapping of the magnocellular and parvocellular subdivisions of human LGN. NeuroImage. 2014; 102p2:358-69. [PubMed: 25038435] The study shows the use of fMRI to identify magnocellular and parvocellular regions of human LGN.

43. Cheong SK, Tailby C, Martin PR, et al. Slow intrinsic rhythm in the koniocellular visual pathway. Proc Natl Acad Sci U S A. 2011; 108:14659-63. [PubMed: 21844334]

44. Martinez A, Hillyard SA, Dias EC, et al. Magnocellular pathway impairment in schizophrenia: evidence from functional magnetic resonance imaging. J Neurosci: Off J Soc Neurosci. 2008; 28:7492-500.

45. Skottun BC, Skoyles JR. Contrast sensitivity and magnocellular functioning in schizophrenia. Vis Res. 2007; 47:2923-33. [PubMed: 17825350]

46. Kim D, Wylie G, Pasternak R, et al. Magnocellular contributions to impaired motion processing in schizophrenia. Schizophr Res. 2006; 82:1-8. [PubMed: 16325377]

47. Doniger GM, Foxe JJ, Murray MM, et al. Impaired visual object recognition and dorsal/ventral stream interaction in schizophrenia. Arch Gen Psychiatr. 2002; 59:1011-20. [PubMed: 12418934]

48. Merigan WH, Maunsell JH. How parallel are the primate visual pathways? Annu Rev Neurosci. 1993; 16:369-402. [PubMed: 8460898]

49. Merigan WH, Maunsell JH. Macaque vision after magnocellular lateral geniculate lesions. Vis Neurosci. 1990; 5:347-52. [PubMed: 2265149]

50. Merigan WH, Katz LM, Maunsell JH. The effects of parvocellular lateral geniculate lesions on the acuity and contrast sensitivity of macaque monkeys. J Neurosci: Off J Soc Neurosci. 1991; 11:994-1001.

51. Merigan WH, Byrne CE, Maunsell JH. Does primate motion perception depend on the magnocellular pathway? J Neurosci: Off J Soc Neurosci. 1991; 11:3422-9.

52. Tolhurst DJ. Reaction times in the detection of gratings by human observers: a probabilistic mechanism. Vis Res. 1975; 15:1143-9. [PubMed: 1166615]

53. Legge GE. Sustained and transient mechanisms in human vision: temporal and spatial properties. Vis Res. 1978; 18:69-81. [PubMed: 664278]

54. Slaghuis WL, Thompson AK. The effect of peripheral visual motion on focal contrast sensitivity in positive- and negative-symptom schizophrenia. Neuropsychologia. 2003; 41:968-80. [PubMed: 12667532]

55. Slaghuis WL, Bishop AM. Luminance flicker sensitivity in positive- and negative-symptom schizophrenia. Exp Brain Res. 2001; 138:88-99. [PubMed: 11374087]

56. Slaghuis WL. Spatio-temporal luminance contrast sensitivity and visual backward masking in schizophrenia. Exp Brain Res. 2004; 156:196-211. [PubMed: 14752582]

57. Revheim N, Butler PD, Schechter I, et al. Reading impairment and visual processing deficits in schizophrenia. Schizophr Res. 2006; 87:238-45. [PubMed: 16890409]

$58 \bullet$. Lima FB, Gracitelli CP, Paranhos A Junior, et al. Evaluation of magnocellular pathway abnormalities in schizophrenia: a frequency doubling technology study and clinical implications. Arq Bras Oftalmol. 2013; 76:85-9. [PubMed: 23828467] The study discussed an interesting and controversial topic about magnocellular pathway deficit using frequency doubling technology in patients with schizophrenia and evaluate the relationship between the deficit in visual processing with socio-demographic factors and clinical factors associated with chronicity, such as negative symptoms, duration of the disease, and antipsychotic drug use.

59. Evans MA, Shedden JM, Hevenor SJ, et al. The effect of variability of unattended information on global and local processing: evidence for lateralization at early stages of processing. Neuropsychologia. 2000; 38:225-39. [PubMed: 10678690]

60. Gutherie AH, McDowell JE, Hammond BR Jr. Scotopic sensitivity in schizophrenia. Schizophr Res. 2006; 84:378-85. [PubMed: 16626942] 
61. Delord S, Ducato MG, Pins D, et al. Psychophysical assessment of magno- and parvocellular function in schizophrenia. Vis Neurosci. 2006; 23:645-50. [PubMed: 16962008]

62. Braus DF, Weber-Fahr W, Tost H, et al. Sensory information processing in neuroleptic-naive firstepisode schizophrenic patients: a functional magnetic resonance imaging study. Arch Gen Psychiatr. 2002; 59:696-701. [PubMed: 12150645]

63. Barch DM, Mathews JR, Buckner RL, et al. Hemodynamic responses in visual, motor, and somatosensory cortices in schizophrenia. NeuroImage. 2003; 20:1884-93. [PubMed: 14642498]

64. Schwartz BD, McGinn T, Winstead DK. Disordered spatiotemporal processing in schizophrenics. Biol Psychiatr. 1987; 22:688-98.

65. Saccuzzo DP, Braff DL. Early information processing deficit in schizophrenia. New findings using schizophrenic subgroups and manic control subjects. Arch Gen Psychiatr. 1981; 38:175-9. [PubMed: 7212944]

66. Keri S, Kelemen O, Janka Z, et al. Visual-perceptual dysfunctions are possible endophenotypes of schizophrenia: evidence from the psychophysical investigation of magnocellular and parvocellular pathways. Neuropsychology. 2005; 19:649-56. [PubMed: 16187883]

67. Schechter I, Butler PD, Silipo G, et al. Magnocellular and parvocellular contributions to backward masking dysfunction in schizophrenia. Schizophr Res. 2003; 64:91-101. [PubMed: 14613674]

$68 \bullet$. Gracitelli CP, de Lima Vaz FB, Bressan RA, et al. Visual field loss in schizophrenia: evaluation of magnocellular pathway dysfunction in schizophrenic patients and their parents. Clin Ophthalmol (Auckland, NZ). 2013; 7:1015-21. This study address an important topic that there is a lower global sensitivity in schizophrenic patients and their parents compared with controls.

69. Tootell RB, Switkes E, Silverman MS, et al. Functional anatomy of macaque striate cortex II. Retinotopic organization. J Neurosci: Off J Soc Neurosci. 1988; 8:1531-68.

70. Skottun BC, Skoyles JR. Are masking abnormalities in schizophrenia limited to backward masking? Int J Neurosci. 2009; 119:88-104. [PubMed: 19116834]

71. Slaghuis WL, Bakker VJ. Forward and backward visual masking of contour by light in positiveand negative-symptom schizophrenia. J Abnorm Psychol. 1995; 104:41-54. [PubMed: 7897052]

72. Phillipson OT, Harris JP. Perceptual changes in schizophrenia: a questionnaire survey. Psycholog Med. 1985; 15:859-66.

73. Harris JP, Calvert JE, Leendertz JA, et al. The influence of dopamine on spatial vision. Eye. 1990; 4(Pt 6):806-12. [PubMed: 2101111]

74. Bodis-Wollner, I. Altered spatio-temporal contrast vision in Parkinson's disease and MPTP-treated monkeys: the role of dopamine. In: Bodis-Wollner, I., editor. Dopaminergic mechanisms in vision. A.R. Liss Inc; New York: 1988. p. 205-20.

75. Brandies R, Yehuda S. The possible role of retinal dopaminergic system in visual performance. Neurosci Biobehav Rev. 2008; 32:611-56. [PubMed: 18061262]

76. Calvert JE, Harris JP, Phillipson OT. Probing the visual system of Parkinson's disease and chronic schizophrenic patients on depot neuroleptic using the tilt after effect. Clin Vis Sci. 1992; 7:119_ 27.

77. Shuwairi SM, Cronin-Golomb A, McCarley RW, et al. Color discrimination in schizophrenia. Schizophr Res. 2002; 55:197-204. [PubMed: 11955979]

78. Buttner T, Kuhn W, Muller T, et al. Visual hallucinosis: the major clinical determinant of distorted chromatic contour perception in Parkinson's disease. J Neural Transm (Vienna, Austria: 1996). 1996; 103:1195-204.

79. Paulus W, Schwarz G, Werner A, et al. Impairment of retinal increment thresholds in Huntington's disease. Ann Neurol. 1993; 34:574-8. [PubMed: 8215245]

80. de Xivry JJO, Lefevre P. Saccades and pursuit: two outcomes of a single sensorimotor process. J Physiol. 2007; 584:11. [PubMed: 17690138]

81. Lisberger SG, Evinger C, Johanson GW, et al. Relationship between eye acceleration and retinal image velocity during foveal smooth pursuit in man and monkey. J Neurophysiol. 1981; 46:229_ 49. [PubMed: 7264712]

82. Fender DH, Nye PW. The effects of retinal image motion in a simple pattern recognition task. Kybernetik. 1962; 1:192-9. [PubMed: 13962910] 
83. Engelken EJ, Wolfe JW. A modeling approach to the assessment of smooth pursuit eye movement. Aviat Space Environ Med. 1979; 50:1102-7. [PubMed: 526212]

84. Baloh RW, Kumley WE, Sills AW, et al. Quantitative measurement of smooth pursuit eye movements. Ann Otol Rhinol Laryngol. 1976; 85:111-9. [PubMed: 944006]

85. Yee RD. Eye movement recording as a clinical tool. Ophthalmology. 1983; 90:211-22. [PubMed: 6866443]

86. Diefendorf, AR.; Dogde, R. Brain. Vol. 31. Oxford Univ. Press; 1908. An experimental study of the ocular reactions of the insane from photographic records; p. 451

87. Mather JA, Putchat C. Motor control of schizophrenics-I. Oculomotor control of schizophrenics: a deficit in sensory processing, not strictly in motor control. J Psychiatr Res. 1982; 17:343-60. [PubMed: 7187778]

88. Bartfai A, Levander SE, Nyback H, et al. Smooth pursuit eye tracking, neuropsychological test performance, and computed tomography in schizophrenia. Psychiatr Res. 1985; 15:49-62.

89. Tanaka M, Fukushima K. Neuronal responses related to smooth pursuit eye movements in the periarcuate cortical area of monkeys. J Neurophysiol. 1998; 80:28-47. [PubMed: 9658026]

90. Hong LE, Tagamets M, Avila M, et al. Specific motion processing pathway deficit during eye tracking in schizophrenia: a performance-matched functional magnetic resonance imaging study. Biol Psychiatr. 2005; 57:726-32.

91. Fox PT, Fox JM, Raichle ME, et al. The role of cerebral cortex in the generation of voluntary saccades: a positron emission tomographic study. J Neurophysiol. 1985; 54:348-69. [PubMed: 3875696]

92. Fukushima J, Fukushima K, Chiba T, et al. Disturbances of voluntary control of saccadic eye movements in schizophrenic patients. Biol Psychiatr. 1988; 23:670-7.

93. Fukushima J, Morita N, Fukushima K, et al. Voluntary control of saccadic eye movements in patients with schizophrenic and affective disorders. J Psychiatr Res. 1990; 24:9-24. [PubMed: 2366215]

$94 \cdot$. Bender J, Reuter B, Mollers D, et al. Neural correlates of impaired volitional action control in schizophrenia patients. Psychophysiology. 2013; 50:872-84. [PubMed: 23790023] The study aimed at identifying neural correlates of Slowed initiation of volitional but not visually guided saccades.

95 •. Picard H, Le Seac'h A, Amado I, et al. Impaired saccadic adaptation in schizophrenic patients with high neurological soft sign scores. Psychiatr Res. 2012; 199:12-8. This study shows that schizophrenic patients with high neurological soft signs scores have reduced saccade adaptation, providing neurophysiological evidence of cerebellar dysfunction.

96. Bolding MS, Lahti AC, White D, et al. Vergence eye movements in patients with schizophrenia. Vis Res. 2014; 102:64-70. [PubMed: 25088242]

97. Abel LA, Levin S, Holzman PS. Abnormalities of smooth pursuit and saccadic control in schizophrenia and affective disorders. Vis Res. 1992; 32:1009-14. [PubMed: 1509692]

98. Silverstein SM, Hatashita-Wong M, Schenkel LS, et al. Reduced top-down influences in contour detection in schizophrenia. Cogn Neuropsychiatry. 2006; 11:112-32. [PubMed: 16537237]

99. Onitsuka T, Niznikiewicz MA, Spencer KM, et al. Functional and structural deficits in brain regions subserving face perception in schizophrenia. Am J Psychiatr. 2006; 163:455-62. [PubMed: 16513867]

100. Gottesman II, Gould TD. The endophenotype concept in psychiatry: etymology and strategic intentions. Am J Psychiatr. 2003; 160:636-45. [PubMed: 12668349]

101. Chen Y, Nakayama K, Levy DL, et al. Psychophysical isolation of a motion-processing deficit in schizophrenics and their relatives and its association with impaired smooth pursuit. Proc Natl Acad Sci U S A. 1999; 96:4724-9. [PubMed: 10200329]

102. Keri S, Kelemen O, Benedek G, et al. Different trait markers for schizophrenia and bipolar disorder: a neurocognitive approach. Psychol Med. 2001; 31:915-22. [PubMed: 11459389]

103. Green MF, Nuechterlein KH, Mintz J. Backward masking in schizophrenia and mania. II. Specifying the visual channels. Arch Gen Psychiatr. 1994; 51:945-51. [PubMed: 7979882] 
104. Green MF, Nuechterlein KH, Breitmeyer B. Backward masking performance in unaffected siblings of schizophrenic patients. Evidence for a vulnerability indicator. Arch Gen Psychiatr. 1997; 54:465-72. [PubMed: 9152100] 


\section{Table 1}

Characteristics of magnocellular and parvocellular pathways

\begin{tabular}{lll}
\hline & Magnocellular & Parvocellular \\
\hline Response & Transitory & Sustained \\
Receptive field & Large & Small \\
Motion perception & Maximum & Minimum \\
High spatial frequency & Minimum & Maximum \\
Low spatial frequency & Maximum & Minimum \\
Color & Minimum & Maximum \\
Response latency & Short & Long \\
Temporal resolution & Fast & Slow \\
\hline
\end{tabular}

를

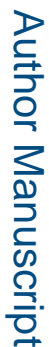




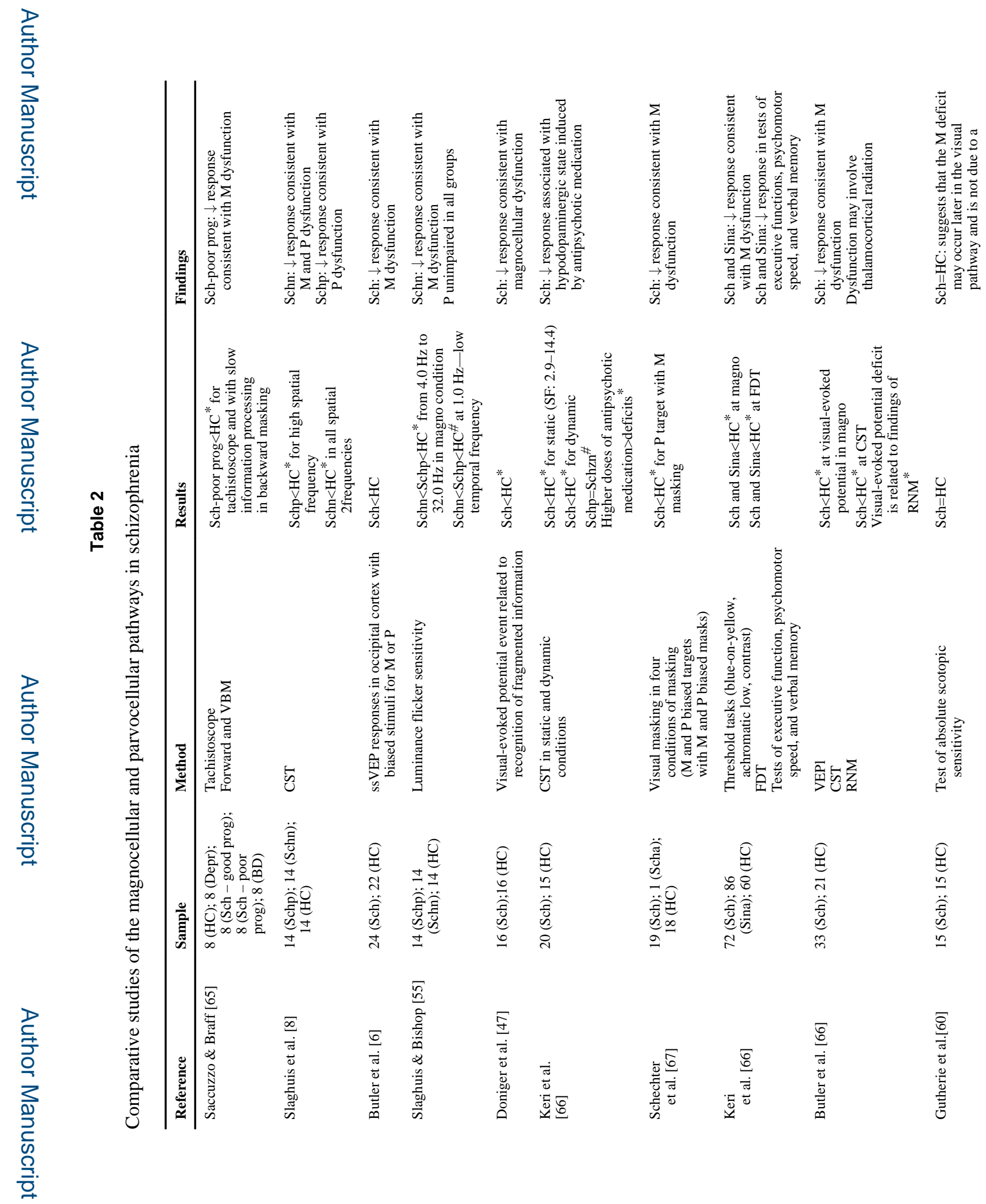

Curr Psychiatry Rep. Author manuscript; available in PMC 2016 May 01. 


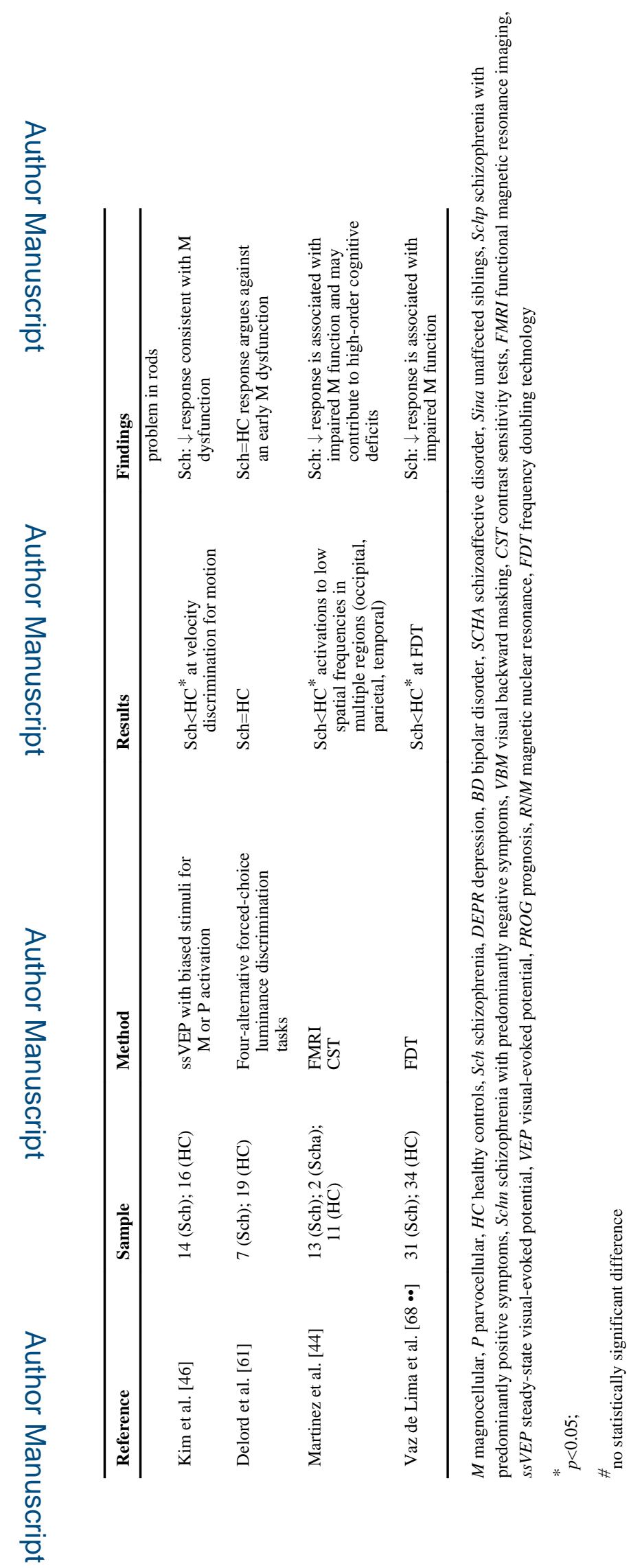

Curr Psychiatry Rep. Author manuscript; available in PMC 2016 May 01. 
Table 3

Characteristics of visual deficits in schizophrenia

\begin{tabular}{|c|c|c|}
\hline & Non-medicated patients & Medicated patients \\
\hline Subjective sensory distortions [72] & $\begin{array}{l}\text { Most common: } \\
\text { First: brightness distortion } \\
\text { Second: motion distortion } \\
\text { Visual distortions tend to report visual } \\
\text { hallucinations }\end{array}$ & $\begin{array}{l}\text { Distortions reduced or removed early in } \\
\text { treatment. } \\
\text { Medications are also beneficial to treatment } \\
\text { of hallucinations }\end{array}$ \\
\hline Contrast sensitivity (CS) [73] & $\begin{array}{l}\text { Global decrease in CS, specially in those } \\
\text { with negative symptoms }\end{array}$ & $\begin{array}{l}\text { Global decrease in } \mathrm{CS} \text {, according to certain } \\
\text { medications }\end{array}$ \\
\hline Saccades and smooth pursuit [97] & Not applicable & $\begin{array}{l}\text { Saccade abnormalities and errors in smooth } \\
\text { pursuit eye movements }\end{array}$ \\
\hline Contour detection [98] & Not applicable & $\begin{array}{l}\text { Worse results on tasks that depend on contour } \\
\text { integration and these deficits may be related } \\
\text { to factors such as illness severity, chronicity, and } \\
\text { degree of disorganized symptoms }\end{array}$ \\
\hline Tilt after effects (TAE) [75] & Undetectable changes & Present \\
\hline Color discrimination [78] [79] & Undetectable changes & $\begin{array}{l}\text { Decrease ability to color discrimination however } \\
\text { no pattern emerged regarding a hue-specific } \\
\text { axis of deficit }\end{array}$ \\
\hline Perception of faces [99] & Not applicable & $\begin{array}{l}\text { Abnormalities in tasks designed to probe facial } \\
\text { processing and recognition }\end{array}$ \\
\hline
\end{tabular}

